Preis MRt. 1.50.

\title{
Wed)jelitempel= gejeb
}

vom 15. Julf 1909

nebit 2 usfïibrungsbejtimmungen und $\mathfrak{B o l l j u g s = \$ p r j ळ r i f t e n t ~}$

Don

\section{Yjblagger}

9gl. Rentamtmann in Ciđjtătt.

Mit Bedjellitempel=Tarif, Gadjregi|ter und 4 Unţängen.

Münđ̆en, Bexlin und Leipzig.

3. Sđ̆weițer Berlag (Ârthur Sellier). 


\title{
Sebald'idhe Iextausgaben bearbeitet unter Mtitwirtung nambafter Juriften.
}

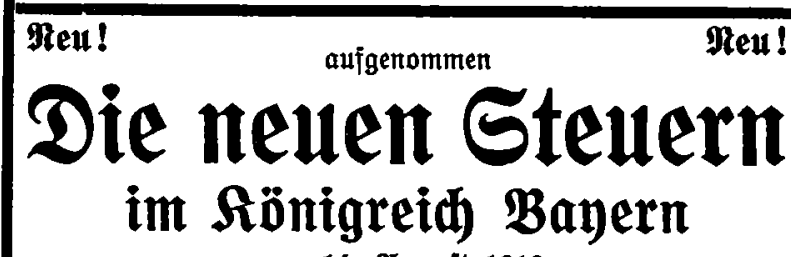

\author{
vom 14. थuguit 1910:
}

I. Einfommeniteuergejeg und Cinjührungsgejes

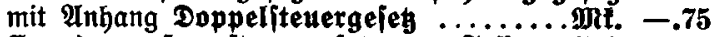

II. Grund = u. Sausitenergejeg, neue Jajilung Mat. -

III. Gewerbeitener $=\mathfrak{u}$. Anpitalrententiteuergef. Dat. -.50

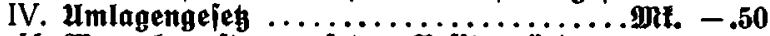

V. Warenhausiteuergejeb, Befigveränderungs: abgabengeles mit $\mathfrak{B}$ ollzugsbetanntma a)ung und

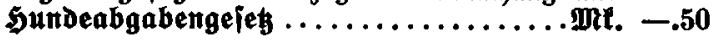

Statt Mt. 3. - Band I mit Vinsgejant mur Mt. 2.50. ausgejajitut enthaltend

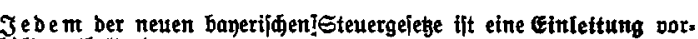

eine Daritellung der widftigiten Beitimntungen,

eiren fiberblid liber bie Entitehungsgeldiate unb bie parla. mentarifide Bebandlung unb

einen Bergleid ber bisherigen mit ben neuen Beitimmungen und ein volitändiges Sadregifter beigegeben.

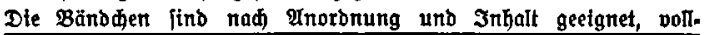

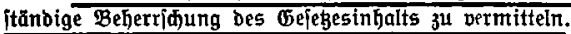

Das Einfübrungsgejes 3 u ben Eejeben über bie biretten Eteuert wurbe mit bem Einfommeniteuergejes als Dem widtigiten Gejeßze ver. etrigt, ebenio bas Reidsopppeliteuergejeb.

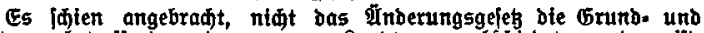
Sausjteuer betreffend, wie es nom Lanotag verabidiebet worden iijt, ionbern bas Grumb = und Das Sausiteucrgefeb in neuer Zextierung

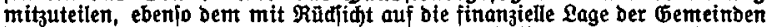
iofort mit ber Berflnoung in Araft getretenen Bejiberänberungsabgaben. gejes die Bolizugsbetantmadung anzureifert.

\section{U. E. Sebald, Berlagshandlung, Nürnberg}

